\title{
ИНСТИНКТЫ, ЭМОЦИИ И ЧУВСТВА: МЕЖДИСЦИПЛИНАРНАЯ ЛИНГВО- ПСИХОЛОГИЧЕСКАЯ МЕГАКЛАССИФИКАЦИЯ
}

\author{
Выработка и классификачия понятий- \\ важнейшие функции науки в описании \\ окружающей нас реальности.
}

А. В. Клименюк

\author{
Непонимание междисциплинарного \\ характера любой науки - роскошь, \\ исследователю непозволительная.
}

А. В. Клименюк

\begin{abstract}
В статье путем ядерно-смыслового анализа многовекового междисциплинарного лингво-психологического знания на основе разработанного автором ортодоксально-альтернативного подхода, в рамках которого ортодоксом является энергия инстинктов человека, а альтернативами - испытываемые индивидом чувства, обоснована гипотетическая мегаклассификация инстинктов, эмоций и чувств. Методология моделирования междисциплинарной мегаклассификации базируется на идее органического синтеза смежных концептуальных представлений философии, когнитивистики, системного подхода, синергетики и кибернетики. Логика структурирования понятийных элементов мегаклассификации включает: (1) их иерархию по вектору движения психофизиологической энергии в последовательности актов зарождения и саморазвития когнитивного процесса речемышления и мыследействия человека как единого неразрывного синергетического процесса; (2) расположение множеств элементов в морфологических рядах каждого их иерархического уровня по вектору (критерию) их энергетического (эмоционально-прагматического) потенциала - от большего к меньшему; (3) прямые и обратные связи между элементами всех уровней классификации как открытой кибернетической системы. В работе показано, что полифункциональный потенциал мегаклассификации как методологического инструментария междисциплинарных когнитивных исследований позволяет использовать её в качестве надежной основы для конвенциализации междисциплинарных понятий когнитивистики; эффективного формирования рабочих классификаций в объеме каждого конкретного когнитивного поиска, играющих роль методологического фундамента в разработке программы и методики экспериментального исследования; обоснования единой стратегии и системы унифицированных тактик проведения статистических когнитивных мегаэкспериментов; создания компьютерной базы данных о результатах исследования инстинктов, эмоций и чувств, индексированных соответственно мегаклассификации; выполнение количественной оценки статистических закономерностей циркуляции психофизиологических энергий индивидов в условиях коммуникации; установления в различных видах когнитивной деятельности индивида нормированных количественных показателей или энергетических порогов психофизиологической энергии, превышение которых приводит к сохранению в его памяти приобретенных (условных) инстинктов и устойчивых комплексов производных чувств; оптимизации дальнейшего продуцирования соответствующих гипотетических конструктов, терминологических определений и математических образов для вербального и графического междисциплинарного описания исследуемых когнитивистами феноменов.
\end{abstract}

Ключевые слова: инстинкты, эмоции, чувства, мегаклассификация, междисциплинарные исследования.

Введение в проблему. Профессиональным исследователям любой области научного знания хорошо известно, что в процессах описания изучаемых явлений неизбежно возникает необходимость в непростой кропотливой работе по классификации вырабатываемых ими понятий. Вполне ясно также, что классификации подлежат преимущественно понятия или термины, закрепившиеся в научной практике в результате их предварительной формальной или неформальной конвенциализации.

Если рассматривать эту проблему непосредственно в сфере когнитивных исследований, то в целом её следует отнести не только к давно неразрешимым, но в силу активного развития самой когнитивистики - к перезревшим, как реально сдерживающую эффективность столь необходимой для неё междисциплинарной диффузии терминологического знания.

В различных формах эмоции изучались и классифицировались практически тысячелетиями. В рамках классического подхода этим вопросам уделяли внимание Платон, Гиппократ, Аристотель, Будда, Р. Декарт, 3. Фрейд, Ч. Дарвин, К. Г. Юнг, А. Адлер, С. Пинкер,

(C) Клименюк А., 2020 
П. Экман, Далай-лама и многие иные не менее известные мыслители. Благодаря этому наука накопила широчайшие представления о номенклатуре эмоций и чувств и обогатилась значительным количеством их частных узкофункциональных классификаций. Однако неоднократно и четко акцентированная К. Г. Юнгом, Н. М. Амосовым, а также К. Э. Изардом, Л. Фельдман Барретт, Далай-ламой, С. Пинкером, Р. Пенроузом и большинством ведущих психологов обеспокоенность отсутствием общей классификации эмоций и чувств, вывела разрешение данной проблемы на уровень острой необходимости. В свою очередь мощное развитие самой когнитивистики как широко междисциплинарной науки с её уникальной потребностью в унификации понятий и классификации изучаемых ею психоэмоциональных феноменов сделала в последнее время актуальность указанного решения самоочевидной.

При этом появились основания утверждать, что в объеме реальных достижений философии, лингвистики, психологии, физиологии, нейрологии, когнитивистики, кибернетики, синергетики и системотехники уже накоплен тот уровень знаний, которого вполне достаточно для построения столь необходимой междисциплинарной системной классификации инстинктов, эмоций и чувств.

Поэтому целью предпринятого нами теоретико-методологического исследования, последовательная логика и результаты которого изложены ниже, было обоснование междисциплинарной лингво-психологической мегаклассификации инстинктов, эмоций и чувств.

Логика теоретического поиска. Поскольку логика формирования такой классификации объективно должна иметь системно-философскую основу, мы вынуждены сделать следующее небольшое отступление.

Известно, что любое искусство синтезирует картину виртуальной реальности путем объединения отдельных присущих или неприсущих ей элементов или сторон в один сколь угодно сложный образ. В отличие от него, наука на основе анализа расчленяет с конкретной целью определенную часть реальности на составные элементы. После этого устанавливает связи между ними. И лишь затем обобщает полученное знание в виде причин и закономерностей функционирования (зарождения, развития и распада [12, с. 127-146; 10, с. 15-34]) такой части реальности, как объекта исследования, четко указывая при этом границы и условия применения полученных результатов.

Понятно также, что в процессе обосновании классификации понятий исследователь вынужден отобрать их рациональный минимум, потенциально достаточный как для описания в целом любого объекта, входящего в объектную сферу определенной науки, так и для рассмотрения множества его отдельных сторон. При этом независимо от цели классификации ее автору необходимо увидеть всю совокупность элементов как единое целое и, почувствовав все возможные уровни и аспекты их взаимодействия, логически верно смоделировать требуемую часть этого целого. Здесь важно не забывать, что построение любой классификации как определенной по форме научной модели имеет смысл лишь в рамках конкретной цели предпринимаемого исследователем поиска. Обоснование же наиболее общей, глобальной или же мегаклассификации значительно сложнее. Это, прежде всего, обусловлено тем, что такая классификация должна обеспечивать все реализуемые в настоящее время и возможные к постановке в будущем цели научных поисков, имеющих или могущих иметь место в изучении сколь угодно большого количества конкретных объектов, входящих в объектную сферу, отражающую определенную область окружающей нас реальности. Кроме того, в процессе построения мегаклассификации ее автор вынужден наряду с профессиональным знанием, владеть искусством введения в ее структурную и смыслосодержательную основу нетрадиционных трансцендентно-креативных элементов. Именно поэтому в научно-методологической литературе процедуру классификации часто называют искусством классификации.

Обозначив таким образом контурно основной философский аспект реализации самого процесса обоснования научной мегаклассификации, перейдем к рассмотрению наиболее важных методологических положений, относящихся к системной организации ее структуры.

Методологические основы поиска. Оптимизация структуры мегаклассификации в форме классической синергетической системы требует, на наш взгляд, особой аналитической дисциплинированности в методологических рассуждениях исследователя. Это в первую очередь 
четкая постановка задачи (цели) классификации, выбор критерия векторности соподчинения ее иерархических уровней и рациональная дифференциация входящих в нее элементов на соответствующие их множества: классы, подклассы, группы и подгруппы.

Говоря об основных общеизвестных методологических требованиях к построению модели любой интеллигибельной системы (в нашем случае - мегаклассификации), напомним, что она должна состоять из отдельных элементов (понятий), входящих в ее структуру и взаимодействующих функционально (в рассматриваемом случае - прямые и обратные связи между элементами системы). Очевидно, что эти требования вполне выполнимы.

Что же касается векторной направленности иерархических уровней элементов мегаклассификации, то их целесообразно располагать традиционно от более абстрактных понятий к более конкретным: инстинкты $\rightarrow$ эмоции $\rightarrow$ чувства. Множества понятий, входящих в каждый из указанных уровней вполне логично дифференцировать на их отдельные классы, подклассы, группы и подгруппы.

Остается отметить, что о синергетической природе мегаклассификации как системе, ее функциях, подфункциях и функциональных возможностях мы будем говорить ниже. Как видим, само по себе удовлетворение методологических требований системного подхода к построению мегаклассификации в форме вербально-графической модели не так уж сложно и с профессиональной точки зрения практически реально.

Несколько иначе обстоит дело с решением проблем оптимизации количественного состава и смыслосодержательного насыщения громадного множества уже наработанных исследователями и непрерывно предлагаемых новых понятий, потенциально пригодных для внесения их в качестве элементов искомой нами мегаклассификации. Это и принуждает нас к более подробному рассмотрению указанных проблем.

Логические предпосылки построения мегаклассификации. Приступая к решению вопроса оптимизации количественного состава элементов мегаклассификации, обратим, прежде всего, внимание на природу и механизмы взаимодействия ряда основных, непосредственно связанных с инстинктами, эмоциями и чувствами психофизиологических и социальных феноменов.

Поскольку независимо от нашего желания результат классификации инстинктов, эмоций и чувств неизбежно обретет статус теоретического концепта, то сформулированная Н.И. Лобачевским в работе «О началах геометрии» необходимость использования в теориях минимального количества конвенциональных понятий [13, с. 39] как методологическое требование в нашем поиске очевидна. В силу этого, пользуясь по ходу изложения уже существующим междисциплинарным терминологическим аппаратом, ниже мы будем вводить лишь минимум новых, ясных и обладающих достаточным уровнем абстракции, научных представлений и соответствующих им понятий.

Ядерно-смысловой анализ понятий. Проведя обзор множества доступных нам определений инстинктов, эмоций и чувств, мы выбрали из них те, ядра смыслов которых наиболее полно и лаконично отражающих сущность понимания указанных феноменов большинством психологов. Рассмотрим с этой точки зрения наиболее типичные формулировки понятия инстинкт.

Инстинкт - совокупность двигательных актов и сложных форм поведения, свойственных животному данного вида, возникающих на раздражения из внешней и внутренней среды организма и протекающих на фоне высокой возбудимости нервных центров, связанных с осуществлением этих актов [21, с. 23].

Инстинкт - комплекс двигательных актов и последовательность действий, свойственных организму данного вида, реализаџия которых зависит от функционального состояния животного (определяемого доминирующей потребностью) и сложивщейся в данный момент ситуации [2, с. 70].

Инстинкт - иерархически организованный нервный механизм, который отвечает на определенные предлагаемые и разрешающие импульсы полностью скоординированными, жизненно важными и свойственными виду движениями (Н. Тинберген) [19, с. 109]. 
Элементарный ядерно-смысловой анализ первого из приведенных выше определений показывает, что понятие инстинкт является научной категорией, характеризующей природную различной степени интенсивности поведенческую реакцию организма человека на раздражители. Смысловое ядро данного понятия включает: реакцию как изменение формы $u$ интенсивности поведения. Вторая формулировка подчеркивает зависимость рефлекторных действий от ситуащии и доминирующей потребности. И, наконец, в третьей цитате акцентируется внимание на том, что инстинктом является иерархически организованный нервный механизм, отвечающий на раздражение скоординированными движениями.

По сути, в этих и всех других определениях инстинкта идет речь об энерго-динамической стороне определенной психофизиологической реакции, запуск которой, как это хорошо известно, сопровождается выбросом гормонов в кровь человека. В связи с этим и возникает логическая необходимость включения понятия инстинкт в искомую нами мегаклассификацию. Это важно, поскольку без определения энергетических характеристик инстинктов междисциплинарное количественное описание психофизиологических феноменов порождения эмоций и чувств теряет свой практический смысл.

Аксиоматические положения анализа. Соотнеся изложенное с реально накопленным современной когнитивистикой междисциплинарным знанием, в дальнейшем изложении под инстинктом мы будем подразумевать присущую организму индивида врожденную или социально обретенную комплексную психо-энергетическую реакиию на раздражение или стимул, вызываюшую неизменную по направленности четко алгоритмическую последовательность актов его речемышления и мыследействия.

Указанное понимание и иные, существующие в современной когнитивистике представления, позволяют нам сформулировать следующие аксиомы, способные служить комплексной концептуальной основой построения искомой мегаклассификации:

- любые раздражения или стимулы, информационно-энергетический потенциал которых не достигает уровня инстинктов экзистенциальной сферы эмоционального мышления индивида, не способны возбуждать какие-либо эмоции и вызывать чувства, а, следовательно, и влиять на процессы его речемышления и мыследействия;

- с функционально-технологической точки зрения саморазвитие инстинктов и эмоций следует рассматривать как единый и неразрывный психо-физиологический процесс, результатом которого являются ощущения, достаточно полно вербализируемые понятиями чувств и способные сохраняться в памяти человека в виде прототипов и соответствующих им аналогов концетов-понятий, обозначающих конкретные чувства;

- инстинкты, равно как и эмоциональные переживания (процессы) человека, по природе их происхождения могут быть как врожденными, так и социально приобретенными;

- психика человека способна функционировать в реверсном режиме: на основе срабатывания инстинкта в процессе саморазвития её эмоционального состояния вырабатывать определенные чувства или же под влиянием чувств путем изменения эмоциональных переживаний вызывать возбуждение того или иного инстинкта;

- в функциональном плане нервная система человека одинаково приспособлена для практически мгновенного энергетического обеспечения запуска в действие как врожденных, так и приобретенных инстинктов его речемышления и мыследействия;

- в процессах речемышления и мыследействия человека психо-физиологическая энергия циркулирует в его организме на основе химико-электрических, электро-химических и электромагнитных явлений;

- природа не дала человеку каких-либо чувств в их чистом виде, но обеспечила каждому индивиду возможность вербального описания их определенных комплексов с учетом (отражением) порядка доминирования в них как минимум трех конвенционально конкретных чувств и каузальных связей между ними.

Пользуясь случаем, отметим, что отсюда непосредственно вытекает применимая как к мыследействию, так и к речемышлению человека идея о существовании двух разновидностей инстинктов: инстинкт-рефлекса (инстинктивного рефлекса) и рефлекс-инстинкта (рефлекторного инстинкта) - к которой, на наш взгляд, близко подошел автор работы [16, 
с. 11-12]. Похоже, что применение этой идеи в решении ряда проблем создания искусственного интеллекта должно дать неожиданно продуктивный результат.

Обоснование классификации инстинктов. Будучи в связи с этим убежденными в том, что до настоящего времени изучено ограниченное количество присущих человеку инстинктов, перейдем непосредственно к анализу существующих их классификаций.

Для этого охарактеризуем кратко основные результаты предварительных дифференциаций уже известных науке инстинктов. Так, в иерархическом плане в большинстве научных публикаций выделяют два-три или один основной (базовый, главный, фундаментальный) инстинкт. А остальные инстинкты относят к автономным, имеющим свои наименования, часто синонимичные определенным чувствам. При этом в зависимости от цели исследования один и тот же конкретный инстинкт может по своему названию быть у разных авторов синонимом и определенного чувства, и мотивации, и стимула, и переживания, и поведенческого акта, и ряда психических состояний.

Возьмем в качестве примера известную, разработанную Уильямом Мак-Дугаллом классификацию инстинктов: бегство (страх); неприятие (отвращение); любознательность (удивление); агрессивность (гнев); самоуничижение (смущение); самоугверждение (воодушевление); родительский инстинкт (нежность); пищевой инстинкт; стадный инстинкт [14, с. 39-69].

Как видим, введенные в неё инстинкты детерминированы понятиями, обозначающими формы поведения или действия индивида, включают дополнительную информацию о доминирующем чувстве, ставшем причиной такого поведения. Отметим, что вследствие неоднозначности таких определений указанная классификация дальнейшего практического применения не получила.

Обратимся ещё к примеру, в котором с целью описания поведенческих феноменов в одной из книг по социобиологии [18] была предложена классификация инстинктов, охватывающая пять их укрупненных групп с сопровождением описания сущности конкретных инстинктов с помощью автономных смысловых модулей. Эта вербальная классификация выглядит так: индивидуальные витальные (жизненные) - отвращение как боязнь: темноты, неизвестности, высоты, змеев, паукообразных, червеобразных, мелких, быстро движущихся животных, хищников, крови, больных, покойников, экскрементов, бурно протекающих природных явлений; репродуктивные: половой, родительский; соичалььые: родственной консолидации, неродственной изоляции, конформизма, вертикальной консолидации, горизонтальной консолидации, клептомании; адаптаџии к эволюционной среде обитания: территориальности, ландшафтных предпочтений, собирательства и поискового поведения, конструктивизма, миграции, самоограничения численности вида, охотничий, агро- и веткультурный, тяги к огню; коммуникативные: мимика и жесты, невербальная звуковая коммуникация, лингвистический [18, с. 40-41, 43-115].

При этом её авторы подчеркивали, что под модулем следует подразумевать функционально выделяющиеся составные части инстинктов. Проще говоря, текст модуля включал указание на причины, условия и примеры реализации рассматриваемого инстинкта.

С методологической точки зрения, авторам столь сложной, мягко говоря, классификации, нелишне было б осознать, что далеко до написания ими книги, термин инстинкт в результате естественной конвенциализации обрёл статус общенаучной категории. Более того, практика использования этого термина в смежных с психологией науках показала возможность исчерпывающего описания роли и особенностей функционирования известных нам инстинктов в поведении человека, обусловленном мотивацией, стимулами, раздражениями и влиянием ряда иных факторов, имеющих место в окружающей реальности. Непонимание этого и привело авторов рассматриваемой классификации к нарушению, как минимум, двух важнейших методологического требований к преемственности научного знания и однозначности значений, используемых исследователем понятий. Невыполнение этих требований, как показывает опыт, и является причиной неоправданно долгого нахождения любой науки на описательной стадии ее развития.

Из изложенного и сущности введенных выше аксиом становится понятно, что в силу высокого познавательного потенциала классического метода ретроспективного изучения инстинктов и на основе накопленного знания для наименования любого известного, равно как и 
познаваемого впервые, инстинкта предпочтительно использовать лишь одно слово. Такое слово должно, например: наиболее емко информировать о состоянии психики индивида (инстинкт страха, агрессии,...), выражать доминирующее чувство (инстинкты любопытства, родительский,...), указывать на поведенческие действия индивида (свободы, доминирования, самоутверждения,...), акцентировать внимание на природе его происхождения (половой, стадный, размножения,...) или раскрывать его мотивационную сторону (выживания, власти,...).

Дополнив полученное таким образом наименование изучаемого инстинкта понятиями врожденный (генетически обусловленный) или приобретенный (социально обусловленный), мы укажем одновременно причину и векторную направленности психо-физиологических процессов его саморазвития. Например: врожденный инстинкт страха, приобретенный инстинкт страха, приобретенный родительский инстинкт, врожденный инстинкт любопытства, приобретенный инстинкт самоутверждения и т. п.

Сформированная нами на таких основаниях классификация инстинктов человека приведена на рис. 1.

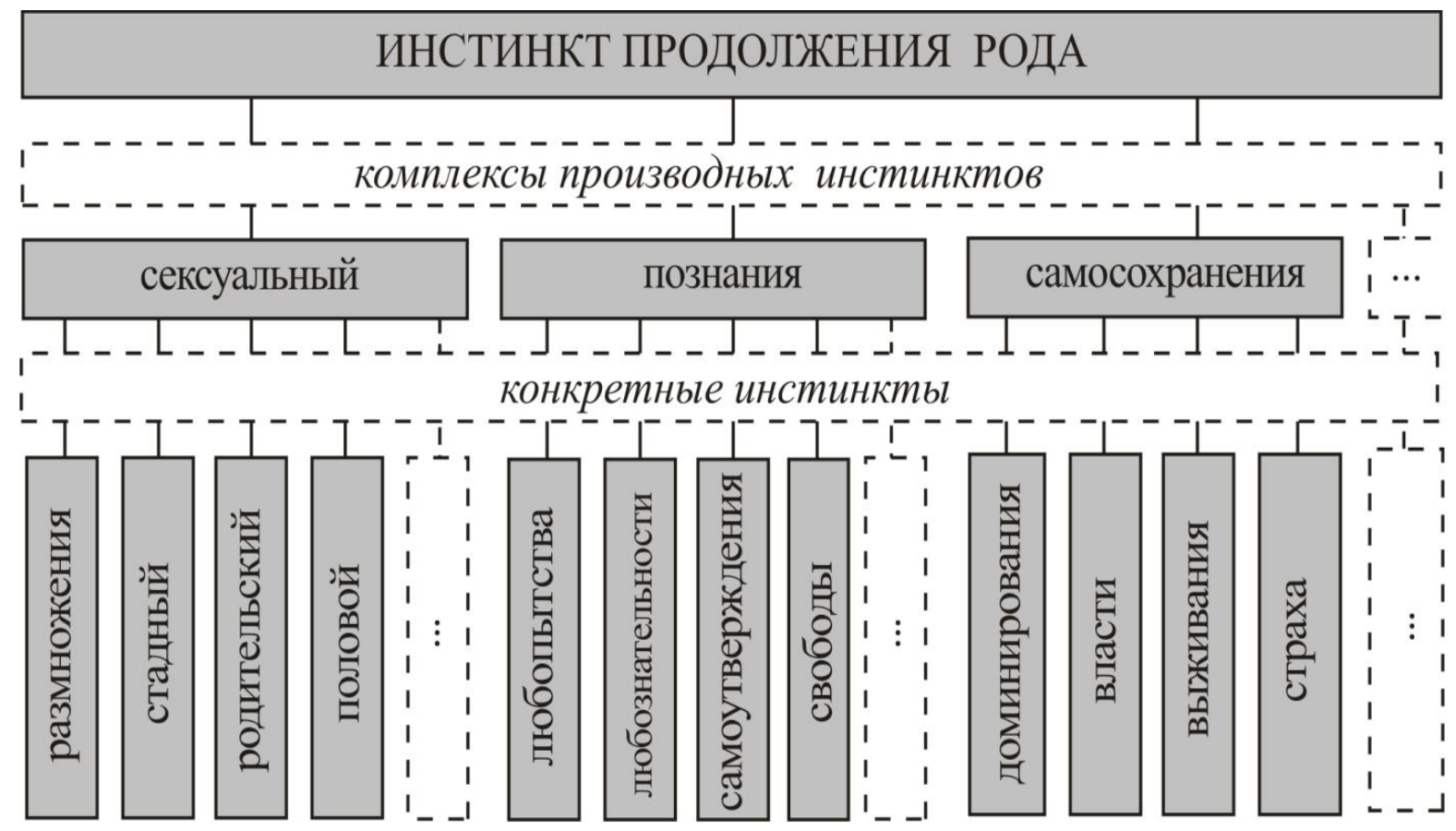

Рис. 1. Междисииплинарная лингво-психологическая классификащия инстинктов человека

Укажем здесь, что расположенный нами на верхнем уровне классификации базовый инстинкт продолжения рода в зависимости от изменений (раздражений и стимулов), имеющих место в окружающей индивида реальности, а также влияния ряда внутренних причин (мотиваций, потребностей и эмоциональных возбуждений) направляет управляемую им психофизиологическую (гормональную и электрохимическую) энергию на возбуждение как минимум двух [6, с. 25; 8] комплексов обслуживающих его производных инстинктов.

Синергетика и механизмы срабатывания инстинктивных реакций. В идеальном случае результатом срабатывания врожденного инстинкта продолжения рода может стать энергетическое возбуждение одной из следующих трех диалектически противоречивых пар комплексных инстинктов: сексуальный и познания; сексуальный и самосохранения; познания и самосохранения.

В большинстве же реальных ситуаций вследствие комбинаций комплексов врожденных и приобретенных инстинктов будут возникать такие их пары: врожденный сексуальный и приобретенный сексуальный; врожденный сексуальный и врожденный познания; врожденный сексуальный и приобретенный познания; врожденный сексуальный и врожденный самосохранения; врожденный сексуальный и приобретенный самосохранения; приобретенный 
сексуальный и врожденный познания; приобретенный сексуальный и приобретенный познания; приобретенный сексуальный и врожденный самосохранения; приобретенный сексуальный и приобретенный самосохранения; врожденный познания и приобретенный познания); (врожденный познания и врожденный самосохранения; врожденный познания и приобретенный самосохранения; врожденный самосохранения и приобретенный самосохранения.

В синергетическом плане факт возбуждения энергии любой из указанных пар комплексных инстинктов означает возникновение первой точки бифуркации - точки начала траектории саморазвития сложного неравновесного психо-энергетического процесса выработки психикой человека реакции на внешние или внутренние раздражения. В этой точке, как известно $[5$, c. 50; 6], зарождается хаос экзистенциального (бессознательного) эмоционального мышления индивида. Он имеет чисто энергетическую природу. При этом сознание человека участия в нем не принимает. Хаос создается вследствие возбуждения комплексными инстинктами определенных популяций нейронов, точнее - нейронных цепей. Движущей силой его дальнейшего саморазвития является разность электрохимических потенциалов. Она возникает между нейронами как эмоциональными точками-концептами, хранящими память о последовательности мышечной реализации двигательных актов, потенциально необходимых для приведения в действие каждого из двух взаимодействующих комплексов инстинктов.

Результатом протекания возникшего таким образом хаоса становится зарождение в нем нового порядка дальнейшего саморазвития совокупности психо-энергетических процессов как единой синергетической системы. Толчок (импульс) к зарождению порядка в систему посылает третий конкретный инстинкт, концепт-прототип которого, обладающий максимальным энергетическим потенциалом, хранится в экзистенциальной (эмоциональной) памяти бессознательной сферы психики индивида. Под его энергетическим управлением зарождается новый порядок саморазвития системы до следующей точки бифуркации (частный аттрактор развития) и до завершения ее функционирования в целом (структура-аттрактор) [10, с. 132-163].

Далее, сконцентрировав в себе энергию неизбежно возникающих в хаосе альтернативных аттракторов возможного саморазвития системы, попавших в конус притяжения зарождающегося наиболее мощного частного аттрактора, и подавляя остальные энергетически слабые альтернативы, этот лидирующий аттрактор обретает свой максимальный психо-энергетический потенциал. Накопленный потенциал и позволяет ему завершить свое развитие во второй точке бифуркации, локализованной на более высоком уровне - в сфере ментального бытия индивида, характеризующегося эмо-рациональным мышлением. Движущими силами саморазвития хаоса во второй точке бифуркации также стают противоречия энергетических потенциалов сформированного в первой точке эмоционального и хранящихся в ментальной памяти индивида прототипов эмо-рациональных концептов.

Однако принципиальное отличие саморазвития хаоса второй точки бифуркации состоит в том, что в его недрах зарождаются не только виды действий, но и их смыслы. Поэтому особенности его саморазвития будут рассмотрены ниже в рамках обоснования классификации чувств человека. Сформировав таким образом необходимые представления о рациональной логике классификации инстинктов (рис. 1), представляющей собой верхний ярус элементов искомой нами мегаклассификации, перейдем к проблеме классификации эмоций.

Классификация эмоций. Решение указанной проблемы также начнем с анализа смыслов, заключенных в приведенных ниже наиболее характерных для психологии определениях эмоций.

Эмоции - субъективные реакции человека и животных на воздействие внешних $и$ внутренних раздражителей, проявляющиеся в виде удовольствия или неудовольствия, радости, cтраха и т.д. [17, с. 1556].

Эмоция (фр. emotion < лат. етоvere возбуждать, волновать) - чувство, переживание, душевное волнение (гнев, страх, радость и т.д.) [15, с. 756].

Смысловое ядро первой классической формулировки - реакция в виде удовольствия (позитивная) или неудовольствия (негативная). Видим, что здесь говорится о конкретных позитивных или негативных реакциях, развивающихся в психике индивида. Вторая формулировка уточняет возможные виды состояния психики: возбуждение, переживание, 
волнение. В том, что оба эти определения описывают некий психофизиологический процесс, не станет сомневаться ни один здравомыслящий исследователь.

В подтверждение этого напомним, что само слово эмоция происходит от латинского movere - двигать, присоединение к которому префикса е дополняет до значения «двигать наружу», что наталкивает на мысль: стремление к действию заложено в каждой эмоции [3, с. 38]. Не менее конкретна и трактовка Оксфордского словаря английского языка, согласно которой эмоция - любое возбуждение или нарушение состояния равновесия, касающееся умственной деятельности, чувств и страстей; любое состояние психического возбуждения [3, с. 489].

Следовательно, изучая эмоции, исследователь должен рассматривать сущность процессов выработки психофизиологических (позитивной или негативной) реакций у человека в непосредственной связи с двумя такими формами их конечной актуализации как речемышление и мыследействие. Более того, любой когнитивист, усвоивший дух современных сентенций системно-синергетического подхода скажет, что с научной точки зрения саморазвитие эмоций является сложным синергетическим процессом. Он также не станет отрицать, что именно внугри этого, движимого психофизиологической энергией саморазвивающегося хаоса, в психической сфере человека и зарождаются его конкретные чувства и готовность его тела к соответствующим физическим действиям.

Поэтому, изучая эмоции, прежде всего, следует отдавать себе отчет в том, что эмоции являются проиессами преобразования энергии инстинктов в чувства.

Важно также понимать, что эмоџии - это психофизиологические процессы, порождающий у человека определенные чувства, влияющие на субъективное восприятие им реальности, которое и предопределяет общую направленность актуализации не полностью контролируемых сознанием актов его речемышления и мыследействия.

В силу такого понимания, описывая эмоциональное состояние психики индивида, квалифицированный исследователь вполне объективно может использовать термины типа: эмоциональный хаос, эмоциональное напряжение, эмоциональная нагрузка, интенсивность эмоциональных переживаний, уровень эмоциональных переживаний, полярность эмоциональной нагрузки, негативные / позитивные эмоции, эмоциональное возбуждение, эмоциональная энергия, эмоциональный потенциал, интенсивность эмоций, продолжительность позитивного / негативного эмоционального состояния и т.п. Таким образом, ему удастся избежать путаницы, возникшей в ряде наук вследствие необоснованного отождествления эмоционального процесса и чувств, возникающих в результате его протекания. Ибо из изложенного выше вполне понятно, что только тот вездесущий в природе синергетический хаос, в результате зарождения порядка в котором и возникают чувства и действия индивида, следует называть эмоциональным состоянием.

Поскольку известно, что любое эмоциональное состояние может вызывать определенные чувства, а чувства, в свою очередь, могут вызывать конкретные эмоциональные состояния, то, пожалуй, нет и объективных оснований смешивать состояние психики с результатом его осознания индивидом.

Тогда, в отличие от традиционной дифференциации эмоций на позитивные и негативные, эмоциональные состояния разумно подразделить на три больших класса: позитивные, неопределенные $и$ негативныле, исходя соответственно из комфортного, переходного или некомфортного состояний психики индивида в целом (см. рис. 2).

Это особенно важно, поскольку позволит дифференцировать подобным образом и чувства, порождаемые в хаосе каждого из трех классов указанных эмоциональных состояний. Подчеркнем, что в таком случае в класс позитивных войдут чувства, благодаря которым психика человека достигает комфортного состояния. Тогда класс негативных образуют чувства, вызывающие в психике человека некомфортные состояния. А к классу неопределенных будут отнесены чувства, возникающие во время перехода психики индивида из её комфортного состояния к некомфортному и наоборот.

Справедливости ради отметим, что потенциально возможен и иной широко эксплуатируемый до настоящего времени вариант - синонимическое сопряжение адекватных терминов, обозначающих классы (категории) сходственных эмоций и чувств. 

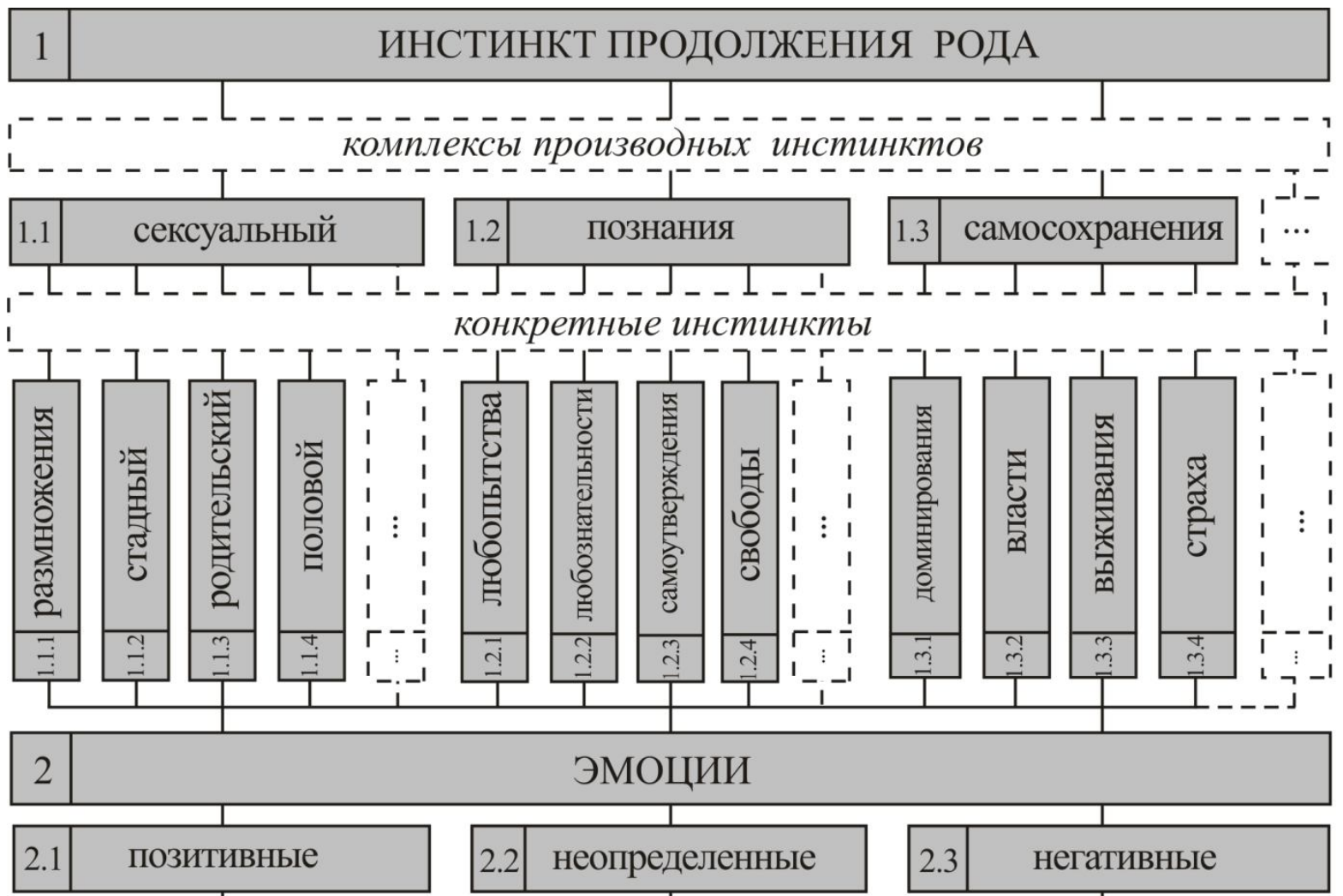

1-- - - - - - - - - - - - L - - - - - - - L - - - I. \begin{tabular}{|l|l|l|}
\hline \multicolumn{2}{|c|}{ низкий } \\
\hline 3
\end{tabular}



Рис. 2. Междисциплинарная лингво-психологическая мегаклассификаџия инстинктов, эмоциий и чувств 
Но в таком случае дальнейшее игнорирование разницы [20, с. 5] между эмоцией как сложным синергетическим процессом и чувством как результатом его саморазвития неизбежно и вполне естественно приведет к профанации самой идеи дальнейших более глубоких междисциплинарных поисков в области когнитивного познания.

Классификация цувств. Отмежевавшись в объеме нашего изложения от классических трюизмов и сопровождающих их терминологических заблуждений психологии, на почве которых со всей очевидностью и зародилась псевдопроблема смешения эмоций и чувств, перейдем непосредственно к логике классификации самих чувств. Для этого проведем ядерносмысловой анализ трактовки приведенного ниже понятия.

Чувства - особый вид сочиально приобретаемых эмочиональных переживаний, носящих отчетливо выраженный предметный характер и отличающцийся сравнительной устойчивостью [4, с. 776].

Смысловое ядро здесь в том, что чувства, во-первых, конкретны (предметны), во-вторых, обретаемы социально. Именно благодаря своей социальной природе чувства и закрепляются в памяти индивида как конкретный легко выражаемый вербально и мимически результат саморазвития в его психике определенных эмоционально стереотипных переживаний.

Поэтому, в строгом понимании, далее под чувствами мы будем подразумевать выражаемый вербально или невербально (интоначия, мимика, жест, поза) закрепленный в памяти индивида типичный результат саморазвития его стереотипных эмочиональных переживаний.

В лекционной практике и публикациях (см., напр., [9, с. 36-38]) на протяжении двух последних десятилетий мы настойчиво обращаем внимание на наш гипотетический причинноследственный концепт, позволивший обосновать две инвариантные алгоритмические схемы, отражающие различные последовательности условного движения психофизиологической энергии человека в процессах трансформации его эмоций в чувства и чувств в эмоции.

Первую схему, в соответствии с которой эмоциональная энергия индивида возбуждается внешними (события, физические воздействия, вербальные действия и т.п.) или внутренними (боль в органах или тканях организма, плохое самочувствие, дискомфорт, болезненная мнительность и пр.) раздражителями можно представить в виде следующей алгоритмической цепочки: раздражение $\rightarrow$ эмоция $\rightarrow$ состояние $\rightarrow$ ощущение $\rightarrow$ осознание $\rightarrow$ чувство $\rightarrow$ реакция. Тогда вторая схема, роль первичного раздражителя в которой выполняет аккумулятивный эффект сознания, примет вид: осознание $\rightarrow$ чувство $\rightarrow$ ощущение состояние $\rightarrow$ эмоция $\rightarrow$ реакция.

Из них легко выделить следующие универсальные реверсивные схемы последовательности движения психофизиологической энергии.

Для врожденных эмоциональных реакций: эмоция $\rightarrow$ состояние $\rightarrow$ ощущение $\rightarrow$ осознание $\rightarrow$ чувство.

Для социально приобретаемых эмоциональных реакций: чувство $\rightarrow$ ощущееие $\rightarrow$ состояние $\rightarrow$ эмоция.

Векторная природа и разнонаправленность указанных схем лишний раз свидетельствует о логической необоснованности отождествления, а, следовательно, о некорректности использования в науках синонимического совмещения понятий эмоция и чувство. Из них становится так же вполне логичным наличие широко распространенного в специальной литературе описания состояний эмоциональных переживаний индивида в терминах или понятиях, тесно связанных с ощущениями и состояниями. Например, Он испытал чувство радости. Он ощутил позитивную эмочиию, породившую чувство радости. Он испьытал инстинктивную эмоцию, вызвавшую чувство страха. Она испьтала инстинктивный страх. Он испьттал радость. Она пережсивала инстинктивную радость. Неопределенность эмочий вызылвала в ней противоречивые чувства стылда и радостии т. п.

Подчеркнем здесь, что причиной неопределенности, т.е. противоречивого саморазвития трудновербализуемой эмоции, может стать не только комплекс порождающих её и различных по природе своего происхождения факторов, но и векторное столкновение энергетически насыщенных комплексов инстинктов (например, страх) и социально обретаемых (например, стыд) комплексов чувств. 
При этом важно понимать, что сложная природа психики человека не допускает возникновения в её сфере каких-либо чувств, взятых в их чистом виде, ибо в сфере эмоционального хаоса в конус притяжения доминирующего чувства всегда попадают порождающие его и неизменно сопутствующие ему чувства. В силу этого любые реально возникающие в психике их комплексы, относимые нами к классам позитивных и негативных, можно объективно обозначать идеальным понятием категориального уровня по доминирующему в них чувству. Например: радость, беда, счастье, горе, удивление, восторг, любовь, уныние, брезгливость, гнев, стыл, страх и т. п. (см. второй ярус классификации рис. 2).

При этом, зная второе по важности в описываемых комплексах чувство, несложно получить и более конкретные наименования комплексов, объединяемых в такие их категориальные группы, как, например, грустная радость, радостная грусть, горькое счастье, радостный восторг, восторженная радость и пр. В связи с ограничением формата графического изложения, такие комплексы производных чувств закодированы нами и введены на третий иерархический уровень их мегаклассификации в форме числовой индексации, указанной в нижней части рис. 2. Декодируются они следующим образом: 3.1.1 - 3.1.4 (счастья восторга), 3.2.2 - 3.1.2 (неуверенной радости), 3.3 .4 - 3.1.4 (брезгливого восторга), 3.1.4 - 3.3.3 (восторженного страха) и т. п.

На четвертом уровне третьего яруса мегаклассификации (яруса классификации чувств) мы расположили кодированные наименования еще более сложных комплексов чувств: 3.1 .3 3.2.1 - 3.3.3 (любовь-сомнение с оттенком страха), 3.2.4 - 3.3.2 - 3.2.1 (неопределенный гнев на фоне сомнения), 3.1.4 - 3.2.3 - 3.1.2 (восторг-смятение с оттенком радости) и т. д.

Или, например: грустная радость с оттенком печали, радостная грусть с оттенком надежды, восторженная радость с оттенком счастья, радостная надежда с оттенком восторга и т.п.

В объеме четвертого иерархического уровня классификации чувств, входящих в класс неопределенных, мы получаем несомненную логическую возможность их следующего именования: например, радость-испуг на фоне надежды, надежда-грусть на фоне печали, грустьлюбовь на фоне испуга, горе-надежда на фоне отчаяния, грусть-любовь на фоне надежды, радость-восторг на фоне счастья и т.д.

В отличие от этого комплексные чувства, входящие в класс неопределенных, следует детерминировать понятиями, отражающими главные (ведущие) чувства, лежащие в основе диалектически противоречивого единства обозначаемых ими реальных комплексов, но уже с учетом четкого доминирования одного из них. Например: радость-испуг, надежда-грусть, радостьнадежда, горе-надежда, горе-испуг, грусть-любовь, любовь-страх, любовь-надежда и т. д.

Приведенного на рис. 2 трехуровневого членения понятий вполне достаточно для обозначения любого комплекса чувств, составляющих их реально существующее множество. Обратимся для примера к известной дискутируемой и сегодня проблеме, связанной со сложностью обозначения множества вариантов чувства ревности, которое, по мнению Д. Гоулмана [3, с. 490], является комбинацией разновидностей гнева с печалью и страхом.

Понимая под ревностью гнев на фоне печали и страха (страха потери любви) и воспользовавшись мегаклассификацией, каждый исследователь без особых затруднений сможет описать существующие альтернативы взаимодействия конкретных чувств, образующих комплексно-категориальное чувство ревности: печальный гнев с оттенком страха, гневный страх с оттенком печали, печальный страх с оттенком гнева, гнев на фоне страха с оттенком печали, страх на фоне печали с оттенком гнева, гнев-страх на фоне печали, страх-печаль на фоне гнева, гнев-печаль на фоне страха и т. д.

Казалось бы, потенциально классификацию чувств можно углубить и до пятого иерархического уровня их производных комплексов. В таком случае получим, например, следующие их комплексы: восторженное удовольствие на фоне упоения удачей с оттенком недоверия, радостной уверенности на фоне счастливого превосходства с оттенком восторга, злого торжества на фоне досады с оттенком брезгливости и т. п. Однако в области лингвистических и психологических экспериментальных исследований, как показывает научная практика, потребности в таком углублении не возникает. 
И, наконец, обратим внимание на то, что (см. рис. 2) в связи с ограничением формата печатного листа в графическую презентацию мегаклассификации нами введены пунктирные прямоугольники. Они показывают, что изображенные на рис. 2 морфологические ряды элементов иерархических уровней классификации, представляющих собой имена комплексов производных инстинктов, конкретных инстинктов, трех классов (позитивные, неопределенные, негативные) доминирующих чувств, а также любых производных комплексов чувств, могут и должны быть расширены.

С учетом методологических правил номенклатура уже известных и вновь вводимых в мегаклассификацию доминирующих чувств с их цифровыми индексами такое расширение необходимо представлять в следующем виде.

В классе 3.1 - позитивных: 3.1.1 - счастья, 3.1.2 - радости, 3.1.3 - любви, 3.1.4 - восторга, 3.1.5 - восхищения, 3.1.6 - гордости, 3.1.7 - обожания, 3.1.8 - сострадания, 3.1.9 - симпатии, 3.1.10 - уважения, 3.1.11 - доверия, 3.1.12 - интереса, 3.1.13 - солидарности, 3.1.14 удовлетворения, 3.1.15 - облегчения, 3.1.16 - наслаждения, 3.1.17 - согласия и т.д.

В классе 3.2 - неопределенных: 3.2.1 - сомнения, 3.2.2 - неуверенности, 3.2.3 - смятения, 3.2.4 - неопределенности, 3.2.5 - беспокойства, 3.2.6 - вины, 3.2.7 - стыда, 3.2.8 - удивления, 3.2.9 - сожаления, 3.2.10 - смущения, 3.2.11 - грусти, 3.2.12 - печали, 3.2.13 - неуютности, 3.2.14 некомфортности, 3.2.15 - неприкаянности и т.д.

В классе 3.3 - негативных: 3.3.1 - горя, 3.3.2 - гнева, 3.3.3 - страха, 3.3.4 - брезгливости, 3.3.5 - ненависти, 3.3.6 - враждебности, 3.3.7 - отвращения, 3.3.8 - протеста, 3.3.9 - отчаяния, 3.3.10 - призрения, 3.3.11 - обиды, 3.3.12 - злости, 3.3.13 - возмущения, 3.3.14 - неприязни, 3.3.15 - недовольства, 3.3.16 - тревоги, 3.3.18 - раздражения, 3.3.19 - досады, 3.3.20 - недоверия, 3.3.21 - неуважения, 3.3.22 - антипатии, 3.3.23 - несогласия, 3.3.24 - неудовлетворения, 3.3.25 беспомощности, 3.3.26- ненужности и т.п.

Добавим, что наименования чувств в каждом их морфологическом ряду следует располагать по вектору уменьшения вызываемой ими эмоциональной нагрузки. Укажем при этом, что подробные правила индексации элементов сложных классификаций изложены нами в работе [10, с. 105-116].

Взаимодействие потоков психофизиологической энергии. Обратимся далее к дискуссионным, до сих пор непростым вопросам о врожденности и социообретаемости (возникновении в результате социального опыта) инстинктов, эмоций и чувств.

Приверженцами, а во многом и продуцентами классических взглядов о врожденности эмоций как разновидности животных реакций были, как известно, Платон, Аристотель, Р. Декарт, Ч. Дарвин и 3. Фрейд. Не смогли преодолеть их магнетизм и такие крупные современные мыслители, как С. Пинкер, П. Экман, Далай-лама, а также существующее сегодня большинство психологов-исследователей и практикующих психотерапевтов.

Это не должно нас удивлять, поскольку в силу здоровой консервативности человеческой культуры большая часть ее конкретных областей (практическая психология, социология, искусство, юриспруденция и т. д.) подобно метастазам уже пронизана идеями классического подхода (см. подробно [1, c. 11-21]), на изменение которых объективно необходимо определенное историческое время.

В то же время, благодаря стремительному развитию когнитивистики, все большее признание в среде исследователей находят высказываемые в той или иной форме современные идеи и о существовании феноменов социальной приобретенности не только чувств, но также эмоций и инстинктов. Так, например, в работах упомянутой выше Л. Фельдман Барретт новый подход предлагается называть теорией конструирования эмоций [1, с. 16].

Если устранить негативные последствия описанного нами синонимического сопряжения понятий «эмоция» и «чувство», имеющего место и в работе Л. Барретт, то можно сказать, что теории конструирования эмоций базируется на аксиоме, согласно которой цувства являются значениями, оперируя которыми мозг индивида способен возбуждать в его психике те или иные эмоции, т. е. «конструировать» их. 
Подчеркнем, что процесс такого конструирования эмоций реализуется по алгоритмической цепочке, выделенной из второй обоснованной нами выше схем: осознание $\rightarrow$ чувство $\rightarrow$ ощущение состояние $\rightarrow$ эмоция $\rightarrow$ реакция.

Напомним, что роль первичного раздражителя в данном случае выполняют усвоенные памятью индивида социально обусловленные значения чувств. Точнее, их следует называть концептами-значениями, поскольку они, как показано в работе [12, с. 213-234; 8], имеют сложную природу и представляют собой комплексы менее сложных концептов, различных по природе своего происхождения.

Эти социально обусловленные концепты могут всплывать в памяти человека в результате его ассоциативно-спонтанного мышления, являться не вполне осознанной реакцией на второстепенную, поступающую по сенсорным каналам информацию, а также возникать в процессах отложенного или акреативного мышления.

Поднимаясь на уровень сознания как наиболее энергетически мощные, эти концептызначения и возбуждают в психике человека те или иные эмоциональные состояния, связанные в памяти индивида в более сложный комплексный прототип чувства-концепта.

Подчеркнем здесь следующее. Во-первых, когнитивно-эмоциональной хаос имеет сугубо психо-энергетическую сущность. Во-вторых, в ответ на достаточно мощные (пороговые) раздражения энергия концептов-инстинктов, хранящихся в эмоциональной памяти бессознательного индивида, возбуждает соответствующие нейронные цепи его мозга. В-третьих, эмоциональный хаос, в котором опредмечиваются последующие акты процессов речемышления и мыследействия как реакция индивида на раздражение, входит в режим максимальной турбулентности в ментальной сфере его психики за счет сложного взаимодействия энергетических потенциалов концептов-инстинктов, концептов-эмоций и концептов-чувств.

Изложенное лишний раз убеждает в том, что эмочиональное состояние - возбужденное состояние психики человека, порождающее чувства и инстинкты или порождаемое ими.

Глубоко понимая это, перейдем к приведенным на рис. 3 схемам взаимодействия потоков психофизиологической энергии в саморазвитии эмоционального хаоса.

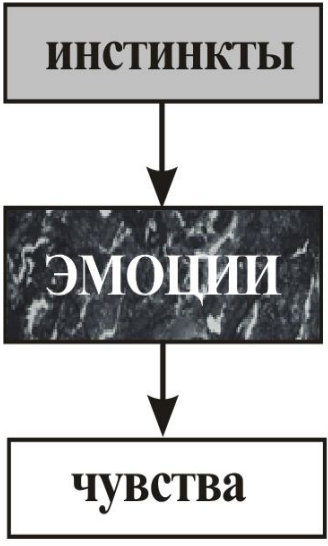

a)

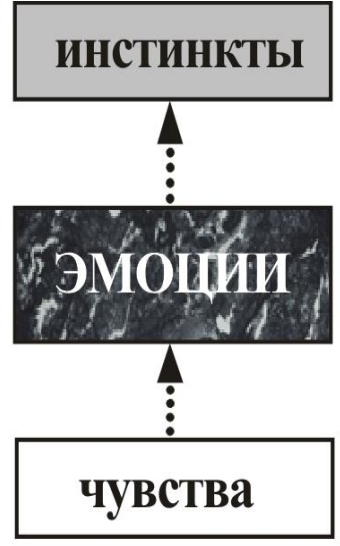

б)

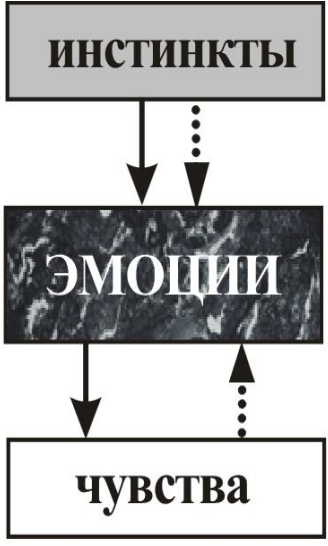

B)

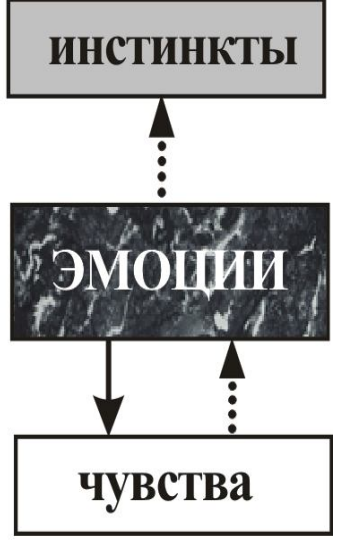

2)

Рис. 3. Идеализированные схемы взаимодействия потоков психофизиологической энергии, обеспечивающих саморазвитие эмочионального хаоса

Схема рис. $3 a$ интерпретирует модель эмоционального хаоса, в основе саморазвития которого преобладает психофизиологическая энергия врожденных инстинктов человека. Строго говоря, эта энергия возбуждает не одну, а сразу несколько (как минимум две) нейронные сети, в нейронах которых возбуждается также и энергия приобретенных эмоциональных концептов. Однако потенциал приобретенных концептов-инстинктов, способных активировать процессы эмо-рационального и рационального мышления индивида, в такой ситуации оказывается, как правило, небольшим, вследствие чего их энергия практически мгновенно подавляется энергией более мощных врожденных концептов-инстинктов, способных порождать в сознании лишь 
концепты чувств-прототипов. Именно по этой схеме в основе своей и реализуются все инстинктивные поведенческие реакции человека.

Векторно-противоположной описанной выше является схема рис. 3б, по которой на основе энергетического взаимодействия чувств в психике человека могут зарождаться социально приобретенные концепты-инстинкты, способные также закрепляться памятью в сфере его бессознательного начала. В таком случае суммарная энергия спонтанного взаимодействия ряда вполне осознаваемых индивидом чувств, усиленная псевдо или вполне реальным сигналомраздражителем, достигает определенного порогового потенциала. Этого потенциала, обычно, оказывается достаточно для того, чтобы подавив табу сознания, психофизиологическая энергия человека вызвала эмоциональный хаос в ментальной сфере его эмо-рационального и рационального мышления. При достижении высокого энергетического потенциала, результат саморазвития зародившегося таким образом эмоционального хаоса закрепляется в бессознательном индивида в виде социально приобретенного аналога концепта-инстинкта.

Несколько иной, но не менее интересной, представляется схема-модель рис. 36 , интерпретирующая наиболее распространенные варианты протекания когнитивных процессов речемышления и мыследействия человека. Условно ее можно назвать схемой приобретения индивидом коммуникативно-чувственного опыта. Она показывает, что возбужденная врожденными (сплошная стрелка) и/или приобретенными (пунктирная стрелка) инстинктами энергия вызывает в психике индивида эмоциональный хаос, в процессе саморазвития которого принимают активное участие четко осознаваемые им чувства (см. пунктирные стрелки). Не будучи подавленными энергией инстинктов, эти чувства-концепты в результате взаимодействия в недрах хаоса с другими родственными или противоречащими им чувствами-концептами способны порождать новые комплексы производных чувств, подобные рассмотренным нами в нижней части мегаклассификации рис. 2. Здесь важно понимать то, что концепты рационального мышления зарождают в хаосе порядок, результат которого осознается и закрепляется в памяти индивида как новое социальное чувство или связанный с ним новый комплекс-концепт производных чувств.

Четвертую, представленную на рис. 3 г схему, с таким же успехом можно назвать моделью порождения социально приобретенных чувственных концептов-инстинктов. Из модели видно, что в процессе саморазвития эмоционального хаоса участвуют определенные энергетически мощные чувства (см. пунктирные стрелки). Такие чувства чаще всего порождаются в результате энергетически насыщенных эстетических, этических, правовых, эмпативных и других ярких переживаний человека. Энергетическая мощность концептов этих чувств способна возбуждать такой потенциал саморазвития эмоционального хаоса, который, с одной стороны, приводит к образованию и закреплению в памяти человека новых комплексовконцептов производных чувств (см. сплошную стрелку). С другой стороны, этого потенциала бывает достаточно и для сохранения в бессознательном психики индивида соответствующих социально приобретенных концептов-инстинктов. Они-то, как правило, и играют роль культурных табу, способных обеспечивать тактичное, толерантное, располагающее поведение человека в его дальнейшей коммуникативной практике.

Не следует игнорировать и тот факт, что, во-первых, в понятиях системного подхода на рис. $3 в$ и 32 изображены схемы нелинейных саморазвивающихся открытых систем с обратной связью энерго-информационных потоков. Во-вторых, подобные, но более подробные схемы таких прямых и обратных потоков могут без затруднений быть указаны и между элементами мегаклассификации инстинктов, эмоций и чувств (рис. 2) в виде соответствующих им древ связей. В таком варианте обоснованная нами мегаклассификация может быть использована уже в качестве кибернетической модели.

При этом исследователь, использующий мегаклассификацию как кибернетическую модель, не должен забывать, что, будучи сложными бессознательными реакциями, по природе своего происхождения инстинкты человека могут быть врожденными и приобретенными; являясь преимущественно энергетическими процессами, преобразующими энергию инстинктов в чувства и саморазвиваясь по законам синергетики, эмоции характеризуются зарождением в 
экзистенциальном хаосе с присущем ему преобладанием бессознательных элементов, рационального начала психики человека в форме эмо-рационального мышления; сознание способно контролировать результаты рационально-логических актов когниции индивида и частично табуировать энергетику бессознательных актов его речемышления и мыследействия; конечный результат саморазвития любого когнитивного хаоса особо жестко зависит от начальных условий его зарождения; объективность ретроспективных результатов когнитивных поисков может быть достигнута лишь при условии четкого понимания исследователем диалектических противоречий, имеющих место между оценками изучаемых событий субъектом и объектом научных наблюдений.

Такое понимание когнитивных явлений позволит методологически верно определить входы и выходы кибернетической системы [10, с. 105-131], а также возмущающие и управляющие воздействия, оказывающие определяющее влияние на особенности ее синергетического саморазвития.

Кроме того, следует обращать особое внимание на природу происхождения исследуемого чувства, поскольку одинаково называемые в быту социально приобретенные чувства испытываются различно по отношению к себе или к другому (радость, жалость, гордость, стыд и т. д.) и могут быть объективно описаны лишь как производные комплексы чувств. Важно понимать причину и механизмы возникновения конкретно изучаемых чувств. Так, страх, испытываемый человеком при нападении зверя, резко отличается от его же страха потерять доверие ближнего. В первой ситуации срабатывает врожденный инстинкт (индивид испытывает животный страх) и реакция (бежать, замереть или атаковать) носит автоматический характер исключающий участие сознания (см. схему рис. $3 a$ ). Во втором случае (см. схему рис. 3в) доминирует социально приобретенный инстинкт и реакция индивида частично или в полной мере контролируется его сознанием. Необходимо также четко представлять разницу между способностями человека испытывать такие чувства боли, как физическая (врожденная - схема рис. $3 a$ ), душевная (индивидуально субъективно приобретаемая - схема рис. 32, коррелирует с добротой) и духовная (социально приобретаемая - схема рис. 32, порождается стремлением к познанию). Такая глубокая и исчерпывающая дифференциация чувств становится вполне реальной на основе использования понятийного аппарата, обоснованного нами выше в объеме формирования мегаклассификации.

Выводы. Оценивая полифункциональный потенциал разработанной мегаклассификации в целом, легко понять, что, являясь универсальным методологическим инструментарием междисциплинарных когнитивных исследований, она способна служить надежной основой для конвенциализации междисциплинарных понятий когнитивистики; эффективного формирования рабочих классификаций в объеме каждого конкретного когнитивного поиска, играющих, как известно, роль методологического фундамента в разработке программы и методики экспериментального исследования; обоснования единой стратегии и системы унифицированных тактик проведения статистических когнитивных мегаэкспериментов; создания компьютерной базы (тезауруса) данных о результатах исследования инстинктов, эмоций и чувств, индексированных соответственно их мегаклассификации; изучения и количественной оценки статистических закономерностей циркуляции психофизиологической энергии индивида в условиях типичных коммуникаций и взаимодействий; установления в различных видах когнитивной деятельности индивида нормированных количественных показателей или энергетических порогов психофизиологической энергии, превышение которых приводит к сохранению в его памяти приобретенных инстинктов и устойчивых комплексов производных чувств; системного планирования и выполнения последующих междисциплинарных когнитивных научных исследований объектов любой конкретной области реально существующей практически необозримой объектной сферы психо-социо-физиологических явлений; оптимизации дальнейшего продуцирования соответствующих гипотетических конструктов, терминологических определений и математических образов для вербального и графического междисциплинарного описания исследуемых когнитивистами феноменов и т.п. 
В заключение отметим, что, создавая мегаклассификацию, мы намеривались получить не бессмысленный вариант «объятия необъятного», а обосновать вполне определенный методологический инструментарий для правильного построения рабочих классификаций системы последующих междисциплинарных когнитивных научных исследований объектов любой конкретной области реально существующей практически необозримой объектной сферы психосоцио-физиологических явлений.

References

1. Barrett, Liza. 2018. Yak narodzhuyutsia emotsii. Kharkiv: Family leisure club.

2. Danilova, Nina and Alevtina Krilova. 1997. Physiology of the higher nervous system. Moscow: Teaching literature.

3. Goleman, Daniel. Emotional intelligence. Kharkiv: Vivat.

4. Ilyichov, Leonid. (Ed.). 1983. Philosophic encyclopedic dictionary. Moscow: Encyclopedia.

5. Kalyta, Alla. 2016. Speech energetics. Kyiv: Kafedra.

6. Kalyta, Alla and Aleksandr Klymenyuk. 2019. "Methodology of modelling cognitive processes of the individual's speaking-and-thinking activities". Studia philologica 12: 13-29.

7. Kalyta, Alla and Aleksandr Klymenyuk. 2019. "Methodological energetic approach to studying speech universals". Scientific papers of V. N. Karazin Kharkiv national university 88: 8-18.

8. Kalyta, Alla and Aleksandr Klymenyuk. 2019. "Methodological potential of the cognitive model of the person's spiritual being pyramid”. Cognition, communication, discourse, 18: 46-59. DOI: 10.26565/2218-2926-201918-04.

9. Klymenyuk, Aleksandr. 2004. "A methodological aspect of the problem of emotions and feelings differentiation". Dynamics of scientific research, 10: 36-38.

10. Klymenyuk, Aleksandr. 2005. Methodology and methods of a scientific research. Kyiv: Millennium.

11. Klymenyuk, Aleksandr. 2009. "Models of conceptual spheres and mechanisms of a person's cognitive thinking". Scientific notes 81(3): 88-104.

12. Klymenyuk, Aleksandr. 2010. Knowledge, learning, cognition. Ternopil: Pidruchnyky i posibnyky.

13. Laptev, Boris. 1976. "Copernicus of Geometry". Science and life 5: 38-40.

14. MacDougall, William. 2003. An Introduction to Social Psychology. Mineola, N. Y.: Dover Publication.

15. Petrov, Phyodor. (Ed.). 1964. Dictionary of foreign words. Moscow: Soviet encyclopedia.

16. Pinker, Steven. 2004. The language instinct. Moscow: Editorial URSS.

17. Prohorov, Aleksandr. (Ed.). 1987. Soviet encyclopedic dictionary. Moscow: Soviet encyclopedia.

18. Prototopov, Anatoliy and Aleksey Vyasovskyi. 2011. Human being's instincts: (An attempt to describe and classify). Yakutsk: Dany AlmaS Publishing.

19. Röell, D. René. 2000. The World of Instinct: Niko Tinbergen and the Rise of Ethology in the Netherlands (19201950). Assen: Van Gorcum.

20. Siddharthan, Advaith, Nicolas Cherbuin, Paul Eslinger, Kasia Kozlowska, Nora Murphy \& Leroy Lowe. 2018. "WordNet-feelings: A linguistic categorisation of human feelings". CoRR abs/1811.02435.

21. Slonim, Abram. 1967. Instinct: Mysteries of the innate behavior of the body. Leningrad: Science.

Клименюк Олександр. Інстинкти, емоції i почуття: міждисциплінарна лінгво-психологічна мегакласифікація. У статті шляхом ядерно-смислового аналізу багатовікового міждисциплінарного лінгвопсихологічного знання на основі розробленого автором ортодоксально-альтернативного підходу, в межах якого ортодоксом є енергія інстинктів людини, а альтернативами - почуття, що відчуває індивід, обгрунтовано гіпотетичну мегакласифікацію інстинктів, емоцій і почуттів. Методологія моделювання міждисциплінарної мегакласифікації базується на ідеї органічного синтезу суміжних концептуальних уявлень філософії, когнітивістики, системного підходу, синергетики і кібернетики. Логіка структурування понятійних елементів мегакласифікації охоплює: (1) їхню ієрархію по вектору руху психофізіологічної енергії відповідно до послідовності актів зародження і саморозвитку когнітивного процесу породження мовлення під час мислення і мисленнєвого проектування дій людини як єдиного нерозривного синергетичного процесу; (2) розташування множин елементів у морфологічних рядах кожного їхнього ієрархічного рівня по вектору (критерію) їхнього енергетичного (емоційно-прагматичного) потенціалу - від більшого до меншого; (3) прямі і зворотні зв'язки між елементами всіх рівнів класифікації як відкритої кібернетичної системи. У роботі показано, що поліфункціональний потенціал мегакласифікації як методологічного інструментарію міждисциплінарних когнітивних досліджень дозволяє використовувати ії як надійне підгрунтя для конвенціалізації міждисциплінарних понять когнітивістики; ефективного формування робочих класифікацій в обсязі кожного конкретного когнітивного пошуку,які відіграють роль методологічного фундаменту в розробці програми й методики експериментального дослідження; обгрунтування єдиної стратегії і системи уніфікованих тактик проведення статистичних когнітивних мегаекспериментів; створення комп'ютерної бази даних про результати дослідження інстинктів, емоцій і почуттів, індексованих відповідно до мегакласифікації; виконання кількісної оцінки статистичних закономірностей циркуляції психофізіологічних енергій індивідів в умовах комунікації; установлення в різних видах когнітивної діяльності індивіда нормованих кількісних показників або енергетичних порогів психофізіологічної енергії, перевищення яких призводить до збереження в його пам'яті набутих (умовних) 
інстинктів і стійких комплексів похідних почуттів; оптимізації подальшого продукування відповідних гіпотетичних конструктів, термінологічних визначень і математичних образів для вербального і графічного міждисциплінарного опису досліджуваних когнітивістами феноменів.

Ключові слова: інстинкти, емоції, почуття, мегакласифікація, міждисциплінарні дослідження.

Klymenyuk Aleksandr. Instincts, Emotions and Feelings: an Interdisciplinary Lingual-and-Psychological Mega-Classification. The paper presents a substantiation of a hypothetical mega-classification of instincts, emotions and feelings. The classification has been worked out by applying the content based semantic analysis of centuries-old interdisciplinary lingual-and-psychological knowledge on the basis of the author's orthodox-and-alternative approach, the orthodox element being represented by the energy of human instincts, while the alternative elements signify the feelings experienced by the individual. The methodology for modeling an interdisciplinary mega-classification is based on the idea of organic synthesis of related conceptual views of philosophy, cognitive science, a systemic approach, synergetics and cybernetics. The logical procedure of structuring the conceptual elements of mega-classification comprises the following: (1) the hierarchy of elements along the vector of psycho-physiological energy movement according to the sequence of acts of origin and self-development of the individual's speaking-and-thinking cognitive activities viewed as a single uninterrupted synergetic process; (2) the location of the multitude of elements in the morphological rows of each hierarchical level according to the vector (or criterion) of their energetic (or emotional-and-pragmatic) potential is in the direction from larger elements to smaller ones; (3) direct and reverse links between the elements of all the levels of classification being viewed as an open cybernetic system. The paper shows the multifunctional potential of mega-classification as a universal methodological tool for the interdisciplinary cognitive study that allows the researcher to use it as a reliable instrument for a number of scientific procedures. Such procedures include: conventionalization of the interdisciplinary notions and terms of cognitive sciences; effective formation of working classifications within the scope of each specific cognitive search, which, as is known, performs the role of methodological grounds in the development of any experimental research program and methodology; the substantiation of an integrated strategy and system of the unified tactics for conducting statistical cognitive mega-experiments. The scientific potential of mega-classification also lies in the creation of a computerized data basis of the results of studying instincts, emotions and feelings, being indexed according to their mega-classification as well as in the quantitative evaluation of statistical regularities of the individuals' psycho-physiological energies circulation in typical communicative situations. The mega-classification can serve as a basis for finding out the norms of quantitative indicators, or energetic thresholds of psychophysiological energy characteristics of various types of the individual's cognitive activities, considering that the excess of this energy leads to the fixation of the acquired instincts and stable complexes of the derived feelings in human's memory. The multifunctional potential of the offered mega-classification can be realized in systemic planning and carrying out of the subsequent interdisciplinary cognitive scientific research of the objects of any area of the existing boundless object-sphere comprising psycho-, socio-, and physiological phenomena as well as in the optimization of further generation of corresponding hypothetical constructs, terminological definitions and mathematical images for a verbal and graphical interdisciplinary description of the phenomena studied by cognitive scientists.

Keywords: instincts, emotions, feelings, mega-classification, interdisciplinary research.

DOI: https://doi.org/10.32782/2410-0927-2020-12-19

УДК 81’23:159.937.523

Еліна Коляда, Тетяна Лісінська

\section{БАЗОВІ ПОНЯТТЯ СЕНСОРНОЇ ЛІНГВІСТИКИ}

У статті розглянуто ключові поняття сенсорної лінгвістики, яка вивчає систему мовних репрезентацій фізіологічних показників п'яти органів чуття - зору, слуху, нюху, смаку і дотику. Відчуття відображають властивості предметів і явищ навколишнього світу. За обсягом сприйнятої інформації в ієрархії п'яти сенсорних підсистем людини перше місце посідає зір, друге - слух. Реєстратором результатів сприймання є перцептивні мовні засоби, де лексичний рівень найбільш значимий. Нерівноцінність перцептивних відчуттів, як і різна кількість мовних знаків їх вираження, знаходить своє відображення в словниковому складі мови.

Вербалізатори чуттєвого сприймання в мовній системі морфологічно представлені різними частинами мови: іменниками, прикметниками, дієсловами, прислівниками, оскільки всім повнозначним словам притаманна номінативна функція. 3 огляду на категорійне значення в іменнику сенсорна ознака $є$ опредметненою; прикметник виражає сенсорну ознаку як статичну, невіддільну від предмета; дієслово виражає динамічну сенсорну ознаку; у прислівнику сенсорна ознака - це ознака іншої (процесуальної чи статичної) ознаки.

Інтерес науковців до результатів мовної об'єктивації чуттєвого сприймання породжує перцептивність як лінгвістичну категорію. Базовим для сенсорної лінгвістики є поняття “сенсорний”, що використовується нарівні 3 поняттям “перцептивний”. Однак в англомовній традиції “сенсорний” співвідноситься з відчуттям, а “перцептивний” - зі сприйманням.

(С) Коляда Е., Лісінська Т., 2020 